Published in final edited form as:

Exp Neurol. 2012 January ; 233(1): 79-86. doi:10.1016/j.expneurol.2011.09.035.

\title{
Stress, Depression and Parkinson's Disease
}

\author{
Ann M. Hemmerle ${ }^{a, b}$, James P. Herman ${ }^{b, c}$, and Kim B. Seroogy ${ }^{a, b,{ }^{*}}$ \\ aDepartment of Neurology, University of Cincinnati College of Medicine, Cincinnati, $\mathrm{OH} 45267$ \\ USA

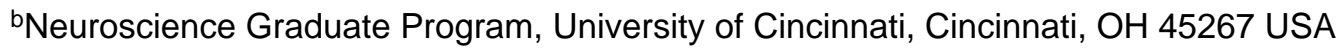 \\ 'Department of Psychiatry and Behavioral Neuroscience, University of Cincinnati College of \\ Medicine, Cincinnati, OH 45267 USA
}

\begin{abstract}
In this review, we focus on the relationship among Parkinson's disease (PD), stress and depression. Parkinson's disease patients have a high risk of developing depression, and it is possible that stress contributes to the development of both pathologies. Stress dysfunction may have a role in the etiology of preclinical non-motor symptoms of PD (such as depression) and, later in the course of the disease, may worsen motor symptoms. However, relatively few studies have examined stress or depression and the injured nigrostriatal system. This review discusses the effects of stress on neurodegeneration and depression, and their association with the symptoms and progression of $\mathrm{PD}$.
\end{abstract}

\section{Keywords}

Glucocorticoids; Chronic variable stress; HPA axis; Dopamine; Neurodegeneration; Non-motor symptoms

\section{Introduction}

For many years, studies of neuropsychiatric disorders have indicated that stress abnormalities are likely involved in the disease pathogenesis. More recently, it has also become apparent that dysfunction of the stress response may have a role in neurodegenerative disorders. Stress dysfunction is particularly intriguing when one considers the very high rate of neuropsychiatric comorbidities in patients with neurodegenerative diseases. For decades, studies have implicated the hypothalamic pituitary adrenal (HPA) axis in a variety of progressive neurodegenerative diseases including Alzheimer's disease, Huntington's disease, amyotrophic lateral sclerosis and Parkinson's disease (PD) (Snyder et al., 1985; Heuser et al., 1991; Patacchioli et al., 2003; Swaab et al., 2005). However, the psychiatric aspect of the disease pathology and the role stress may play in the disease process are relatively understudied. For the purpose of this review, we will

(C) 2011 Elsevier Inc. All rights reserved.

"Corresponding Author: Kim B. Seroogy, Department of Neurology, James J. and Joan A. Gardner Family Center for Parkinson's Disease and Movement Disorders, College of Medicine, Medical Sciences Building, ML 0536, 231 Albert Sabin Way, University of Cincinnati, Cincinnati, OH 45267 USA, Telephone: 1-513-558-7086, Fax: 1-513-558-7009, kim.seroogy@uc.edu.

Publisher's Disclaimer: This is a PDF file of an unedited manuscript that has been accepted for publication. As a service to our customers we are providing this early version of the manuscript. The manuscript will undergo copyediting, typesetting, and review of the resulting proof before it is published in its final citable form. Please note that during the production process errors may be discovered which could affect the content, and all legal disclaimers that apply to the journal pertain. 
focus on PD, the high occurrence of depression in the disease, and the function of the stress response in the development of both PD and depression.

\section{Neurobiological aspects of stress and depression}

Appropriate responses to external or internal adversity (i.e., the 'stress response') are critical for adaptation and survival. The stress response involves the activation of multiple bodily systems, the most prominent of which are the HPA axis and autonomic nervous system. Activation of the HPA axis creates a neuroendocrine cascade that results in the elevation of glucocorticoid levels. Glucocorticoids (cortisol in humans and primarily corticosterone in rats and mice) subserve important adaptive functions during stress exposure (e.g., glucose mobilization), and also provide negative feedback regulation of HPA axis activation, thereby limiting their own secretion. While initially adaptive, protracted activation of the stress response contributes to physiological abnormalities and may be involved in the development of disease states (Herman and Cullinan, 1997). Mood disorders are often preceded by stressful life events, whether environmental or physiological (Kendler et al., 1999; Gold and Chrousos, 2002), and chronic stress is considered an important risk factor for depression (McGonagle and Kessler, 1990). Notably, glucocorticoid receptors (GR) are localized to many regions involved in depressive and neurological pathologies, including the prefrontal cortex (PFC), hippocampus, striatum, limbic system, nucleus accumbens, and ventral midbrain (Herman, 1993; Van Craenebroeck et al., 2005), suggesting the potential for glucocorticoids to play a role in disease processes.

Aberrant neuroplasticity in limbic brain regions involved in emotion and memory, such as the hippocampus, PFC, and amygdala, appear to contribute to the pathophysiology of mood disorders (e.g., Duman, 2002). Limbic-driven HPA axis hyperactivity is associated with major depresssion (Gold et al., 1988), whereas HPA hypoactivation is often seen in PTSD (Yehuda et al., 2006), suggesting that optimal regulation of glucocorticoid secretion is required for appropriate adaptation to stress. Glucocorticoid hypersecretion can act to disrupt normal hippocampal and cortical function. In vitro, hippocampal cells are more susceptible to subsequent neurotoxin exposure when cells are first exposed to glucocorticoids (Sapolsky et al., 1988). In vivo, exposure to stress results in dendritic atrophy in key limbic regions associated with the pathology of depression, including the PFC and hippocampus (Magariños and McEwen, 1995a, b; Wellman et al., 2001; Duman, 2002). The hippocampus is implicated in mood disorders as well as learning and memory and HPA axis regulation, both of which are impaired in depression (Duman and Monteggia, 2006). The hippocampus is interconnected with the PFC and amygdala, with the PFC playing an inhibitory role on the HPA axis, and the amygdala having excitatory connections (Ulrich-Lai and Herman, 2009). Therefore, effects on the hippocampus can have long-term consequences on glucocorticoid homeostasis.

As noted above, stress can cause dendritic atrophy, particularly in GR-rich regions such as the hippocampus (Magariños and McEwen, 1995a,b). Mineralocorticoids, however, do not produce cellular atrophy (Gould et al., 1991), suggesting the GR as the primary mediator of pathology. Aged rats have reduced GR expression (Sapolsky et al., 1983; Landfield and Eldridge, 1989) and signaling (Murphy et al, 2002) in the hippocampus. It is hypothesized that the loss of GR signaling causes elevated corticosterone secretion via loss of negative feedback (Sapolsky, 1994). Chronic corticosterone administration and chronic stress also decrease hippocampal GR expression, suggesting a link between elevated steroid secretion, stress and the aging process (Sapolsky et al., 1985). Notably, Meaney's group demonstrated a correlation between elevated corticosterone and memory deficits in aged rodents, suggesting that elevated glucocorticoids are linked to hippocampal pathology (Issa et al., 1990). 
Chronic stress and corticosterone also cause changes in neuronal morphology in other GRrich limbic sites. Both treatments reduce dendritic complexity in the medial PFC (Wellman et al., 2001; Radley et al., 2004; Cerqueira et al., 2005; Dias-Ferreira et al., 2009), which is known to be involved in inhibition of stress responses and control of emotionality. Dendritic atrophy is also observed within corticostriatal circuits in animals that experienced chronic stress, including the dorsal medial striatuam, whereas dendritic hypertrophy is seen in the dorsal lateral striatum (Dias-Ferreira et al., 2009). Glucocorticoids and chronic stress increase dendritic complexity in the amygdala, a region positively linked to fear, anxiety and depression (Vyas et al., 2002; Mitra and Sapolsky, 2008). To date, neuroplasticity studies have focused on sites involved in emotion, memory and stress regulation. Due to the widespread distribution of the GR, however, other regions of the brain may be susceptible to deleterious or aberrant effects of glucocorticoids/stress on morphology and function. These include the striatum and substantia nigra, regions central to PD pathology.

In humans, imaging studies indicate decreased hippocampal volume in depressed subjects, consistent with neuronal atrophy (Sheline et al., 1996; Sheline, 2003; Duman 2004a,b). Volumetric changes also occur in the amygdala and PFC of patients with depression (Salvadore et al., 2001; Kanner et al., 2004; Tang et al., 2007). Subregions of the PFC (e.g., subgenual anterior cingulate cortex) are hyperactive in depression, and inactivation by deep brain stimulation causes remission of depressive symptoms, linking this stress-targeted region in the pathogenesis of the disease (Mayberg et al., 2005). Antidepressant treatment may be effective by protecting against the loss of hippocampal (Sheline, 2003) and importantly, frontal cortical volume (Lavretsky et al., 2005).

Exposure to acute and chronic stress decreases adult hippocampal neurogenesis (Duman, 2004a,b). As exposure to stress decreases new cell production in the hippocampus of animals, this may explain the decrease in total cell volume observed in humans (Fuchs et al., 1998). In contrast, both antidepressant treatment and environmental enrichment can increase neurogenesis in the adult hippocampus and antidepressant treatment can block/reverse the decrease of neurogenesis caused by stress (Malberg et al., 2000; Brown et al., 2003; Duman, 2004a).

Alterations in neurotrophic factor expression in limbic regions may also contribute to the presentation of depressive symptoms (Nestler et al., 2002). After exposure to chronic stress, brain-derived neurotrophic factor (BDNF) mRNA levels are decreased in the hippocampus whereas neurotrophin-3 (NT-3) mRNA levels are increased (Smith et al., 1995; Song et al., 2006). The systemic administration of corticosterone also decreases expression of BDNF mRNA in the hippocampus, but does not affect NT-3 expression (Schaaf et al., 1997, 1998). The observed decrease in BDNF mRNA levels in the hippocampus after both acute and chronic stress can be reversed by chronic, but not acute treatment with antidepressants (Nibuya et al., 1995). Unpredictable footshock, social isolation, swim stress and maternal deprivation all reduce BDNF expression in the hippocampus, indicating that the decrease is not a stressor-specific effect (Duman and Monteggia, 2006). Chronic mild stress also links the alterations of BDNF levels together with a neuroinflammatory environment, as decreases in BDNF expression and increases in inflammation are both present in animals after chronic stress (Kubera et al., 2011). Neuroinflammation, itself, is thought to be involved in the formation of depression (Maes et al., 2009).

Approximately $50 \%$ of depressed patients exhibit HPA axis dysfunction, characterized by impaired feedback regulation of corticosteroid secretion (Kanner et al., 2004). The lack of dexamethasone suppression indicates dysfunction of the HPA axis, which is likely caused by increased stimulation of the pituitary gland by hypothalamic drive (Kathol et al., 1989). Patients with major depression have elevated corticotropin-releasing hormone (CRH) 
mRNA expression and cell number in the hypothalamus as well as increased levels of CRH in cerebrospinal fluid (Nemeroff et al., 1984; Swaab et al., 2005). The question arises whether HPA axis dysregulation causes depression or whether the emotional disturbances present in the disorder result in stress dysregulation (Van Craenenbroeck et al., 2005).

Animal models of depression have been employed to uncover the relationship between stress and depression symptomatology. Our group employs a chronic variable stress (CVS) model, which subjects rats (or mice) to various mild stressors in an unpredictable manner over an extended period of time (Katz et al., 1981; Herman et al, 1995; Willner, 2005) and affects many molecular and cellular pathways that can generate neuronal injury (see Fig. 1). Chronic stress regimens result in hypersecretion of corticosterone and ACTH, as well as adrenal hypertrophy (Herman et al., 1995). Similarly to what is observed in humans, CRH levels are elevated in the hypothalamic paraventricular nucleus (PVN) of animals exposed to chronic variable stress (Herman et al., 1995; Wang et al., 2010). The CVS paradigm also causes increases of oxidative damage in several areas, including cortical regions, hippocampus and striatum (Lucca et al., 2009a), paralleling observations seen in depressed patients (Forlenza and Miller, 2006). Chronic restraint stress, CVS and chronic administration of corticosterone all result in retraction of apical neuronal dendrites within the hippocampus (Magariños and McEwen, 1995a,b). However, unlike chronic restraint, CVS prevents habituation of the stress response and results in adrenal hypertrophy and thymus atrophy (Magariños and McEwen, 1995a).

The use of the CVS model results in a decrease in sucrose intake and reduced conditioned place preference (signs of anhedonia), decreases in sexual behavior and grooming, and sleep dysfunction, all of which have correlates to depression in humans (Papp et al., 1993; Willner, 2005). Importantly, chronic, but not acute, treatment with antidepressants results in reversal of these behaviors (Willner, 2005), another feature that has parallels in human depression symptomatology. The anhedonic behavior observed after chronic stress can also be reversed by the administration of dopamine agonists (Papp et al., 1993). Dopamine pathways are a part of the reward system, and the effects of stress on reward perception possibly occurs because of the interaction between the HPA axis and dopaminergic systems (Van Craenebroeck et al., 2005).

\section{Stress and dopamine neurons}

In some suicide victims, dopamine levels are elevated in the hypothalamus (Arranz et al., 1997). After receiving the dopamine receptor agonist apomorphine, patients with both depression and elevated cortisol levels exhibit a blunted cortisol response, suggesting cortisol feedback deficits may be associated with dopamine receptor dysfunction in the hypothalamus (Duval et al., 2006). The normal physiology of dopamine in the mesolimbic and mesocortical systems is also disrupted by stress (Pani et al., 2000). In rats, acute restraint stress increases dopamine release in the nucleus accumbens and PFC (Imperato et al., 1990). Acute immobilization increases dopamine levels in the frontal cortex, whereas levels decrease in the striatum and hippocampus (Rasheed et al., 2010). Tail-shock stress increases dopamine efflux in the striatum, nucleus accumbens, and frontal cortex, though to varying degrees (Abercrombie et al., 1989). However, chronic stress generally decreases dopaminergic tone. Prefrontal cortex dopamine content is significantly reduced following CVS (Ziegler et al, 1999). Moreover, chronic unpredictable stress decreases dopamine levels in striatum, nucleus accumbens, and frontal cortex (Rasheed et al., 2010). Chronic cold stress increases efflux of dopamine in the medial PFC, but not in the striatum and nucleus accumbens (Gresch et al., 1994). Restraint stress elevates oxidative stress products in the nigrostriatal system, potentially leading to an increased vulnerability of dopamine neurons (Kim et al., 2005). Together, these studies suggest that interactions between dopamine and 
stress are dependent on intensity and/or duration of stress exposure, with acute stress generally acting to increase dopamine release, whereas chronic stress decreases dopamine content. Additionally, these studies indicate that although acute and chronic stress affect dopamine largely in the rostral forebrain, there are some alterations of dopamine levels found in the striatum and mesolimbic pathway as well (Finlay and Zigmond, 1997).

However, the effects of stress on the injured dopaminergic nigrostriatal system are relatively unexplored. The dysfunction of mesotelencephalic dopaminergic pathways after exposure to stress and/or depression has implications for the pathophysiology of PD; addressing this issue is important, given the comorbidity of PD and depression.

\section{Parkinson's disease and depression}

Parkinson's disease is a progressive neurodegenerative disorder that affects about $1 \%$ of individuals over the age of 65 and is characterized by severe loss of dopaminergic neurons in the nigrostriatal pathway, resulting in motor dysfunction (Weintraub et al., 2008a). The exact etiology of PD is currently unknown, but the greatest risk factor for the disease is aging. While the cardinal motor symptoms of resting tremor, bradykinesia, postural instability and rigidity are the most identifiable manifestations of the disease, a plethora of non-motor symptoms (which can greatly affect the quality of life of patients) may be present as well. One of the most common comorbidities is depression (Weintraub et al., 2008b). The most commonly cited prevalence of depression in PD is between 40-50\% of all PD cases (Cummings, 1992; Lemke, 2008; Aarsland et al., 2009). While the elderly overall have an elevated risk of depression (about 11\%) (Steffens et al., 2009) compared to the general population (about 7\%) (Kessler et al., 2003), there is a considerably enhanced risk of depression in PD. Depression in PD has adverse effects on the quality of life of Parkinson's patients and is one of the most disabling aspects of the disease (Kuopio et al., 2000).

Depression is also associated with worsened motor function and increased disease severity that directly impacts daily living (Giladi et al., 2000; Papapetropoulos et al., 2006; Riedel et al., 2010). However, though the rates of suicidal ideation are elevated in depressed PD patients, actual suicide attempts are uncommon (Kummer et al., 2009).

Despite the fact that almost half of PD patients experience depression, only about 26\% receive medication to treat it (Richard and Kurlan, 1997; Yamamoto et al., 2001). This mismatch of incidence versus diagnosis is likely caused by the overlap in symptoms between the two disorders. Clinicians also often fail to recognize depression or dysthymic disorder in PD (Yamamoto et al., 2001). Both depression and PD symptoms include motor slowing, bradyphrenia (slowness of thought), sleep and appetite disturbances, weight loss, loss of interest and concentration, reduced libido and lack of emotional response (Richard, 2007). The psychomotor retardation that commonly occurs can also mask the presence of depression (Lieberman, 2006). On the other hand, depressive symptoms such as anergy, apathy, insomnia, excessive sleep, and weight loss can also occur in PD patients who are not considered depressed (Richard, 2007). All of the above makes diagnosis and therefore subsequent treatment difficult, and should persuade clinicians to be particularly observant to signs of depression in PD patients.

It is argued that depression in PD is not merely a psychological reaction to being diagnosed with the disease itself, but rather a secondary symptom of the ongoing neurodegeneration (McDonald et al., 2003). Depression in PD does not appear to parallel the progression of the physical symptoms of the disease, suggesting independent processes at work (Brown and Jahanshahi, 1995). Others have found the increased risk for most neuropsychiatric symptoms occurs with increased PD severity, but does not correlate with age or age of onset (e.g., Lieberman, 2006). However, depression occurred in higher rates in patients that developed PD at an early age compared to those with later onset (Giladi et al., 2000; Schrag 
et al., 2003). Moreover, it has been put forth that the comorbidity of PD and depression may be biphasic in nature with peaks early and late during the course of the disease (Richard et al., 2007).

Overall, clinical studies indicate that depression is present in patients at all stages of PD. Thus, it is not known whether depression is a preclinical manifestation of the ongoing neurodegenerative process that occurs before compensatory mechanisms no longer prevent the advent of motor symptoms, or an active component of the neurodegenerative process. One opinion contends that depression precedes the onset of motor symptoms in PD. Indeed, studies found a higher incidence of depression in patients who were later diagnosed with PD than in a comparable control population (Leentjens et al., 2003a). People with depression have a higher rate of being subsequently diagnosed with PD than those with diabetes, a chronic condition, or osteoarthritis, another disease of aging (Nilsson, 2001). Emotional vulnerability may also increase the chances of PD patients developing depression (SerraMestres and Ring, 2002). Another outlook argues that the depression in PD develops after disease diagnosis. More severe motor symptoms as well as longer disease duration are present in PD patients diagnosed with depression compared with non-depressed PD patients (Pålhagen et al., 2008). This could be an indication of a further advanced and widespread disease state (Pålhagen et al., 2008). There is also debate on whether depression appears in $\mathrm{PD}$ as a natural part of the disease process or whether there is a convergence of two independent pathological processes (Leentjens, 2004).

The primacy of the neurodegeneration of dopamine neurons in the nigrostriatal pathway in PD cannot be ignored. However, it is likely that depression in PD is caused by a combination of elements including pathology outside of the nigrostriatal pathway or environmental factors interacting with the nigrostriatal pathology (Schrag, 2006). Other dopaminergic pathways and other neurotransmitters are affected throughout the course of PD and more than likely play a role in the development of non-motor symptoms. Accordingly, the impaired function of noradrenergic and serotoninergic neurons may also play a role in the development of depression in PD (Yamamoto et al., 2001). Norepinephrine and serotonin are the two neurotransmitters most commonly associated with depression pathogenesis. Certain personality traits present in PD patients with depression, such as harm avoidance (anxious behavior), appear to be linked to serotoninergic function (Menza and Mark., 1994). In depression, there is a loss of norepinephrine signal resulting from degeneration of LC projections to the frontal cortex and limbic system (Chan-Palay and Asan, 1989a). In PD, there is also a decrease in the activity and number of neurons of the serotoninergic neurons in the dorsal raphe nucleus and of the noradrenergic neurons in the LC (Lieberman, 2006). A reduction of serotoninergic metabolite levels in the cerebral spinal fluid is found in depressed versus non-depressed PD patients (Mayeux et al., 1984) and there is noradrenergic cell loss both rostrally and caudally (Chan-Palay and Asan, 1989b). Elevated serotonin transporter levels in the striatum and dorsalateral and prefrontal cortices were correlated with depressive symptoms in PD patients, but not with disease severity (Boileau et al., 2008). This emphasizes the possibility of serotoninergic pathology in PD with depression. However, this study did not compare the depressed PD patients to nondepressed PD patients (Boileau et al., 2008). On the other hand, it is unlikely that the loss of serotonin alone plays a role in depression etiology in PD, because SSRIs are not always effective in treating the depression in PD patients, despite often being the first choice for treatment (Yamamoto et al., 2001; Leentjens et al., 2003b).

Additional imaging studies have observed differences in other neurotransmitter systems between PD patients with and without depression. For example, a decrease in cortical acetylcholinesterase activity, a marker of cholinergic innervation, occurs in the cortex of PD patients displaying depressive symptomatology, particularly those that also have dementia 
(Bohnen et al., 2007). A reduction of acetylcholine receptor binding in the cingulate cortex and the frontoparieto-occipital lobe is also found in depressed PD patients (Meyer et al., 2009). Recent imaging studies using specialized magnetic resonance imaging (MRI) techniques also demonstrate differences between depressed and non-depressed PD patients in several brain structures outside the nigrostriatal pathway. For example, reduction of gray matter in PD patients with high apathy scores is seen in several regions including the cingulate and frontal gyruses (Reijnders et al., 2010). White matter is decreased in depressed PD patients in the anterior cingulate and orbitofrontal cortices (Kostić et al., 2010). Using functional MRI, a reduction in the activity of the medial PFC and the left mediodorsal thalamus, as well as an increase in the volume bilaterally of the mediodorsal thalamic nuclei, occur in PD patients with comorbid depression (Cardoso et al., 2009). Similar differences in the mediodorsal thalamus have been found using diffusion tension imaging ( $\mathrm{Li}$ et al., 2010). These areas are all thought to be involved in depression, though it is unknown if it is specifically loss of dopaminergic innervation or more global neurodegeneration that contributes to these regional alterations (Cardoso et al., 2009).

Non-motor symptoms in PD cannot be considered the same as symptoms caused by nondopaminergic pathways (Fox et al., 2009; Chaudhuri and Schapira, 2009). Depressive symptomatology in PD may also be related to dopaminergic dysfunction as dopamine agonists can improve depressive symptoms (Barone et al., 2007; but see Leentjens, 2011). Decreases in dopaminergic transporter availability in the striatum are seen in PD patients with depression (Weintraub et al., 2005; Hesse et al., 2009). This is likely secondary to the dopamine loss in the region, indicating a more extensive cell loss in depressed PD patients (Hesse et al., 2009) and increased basal ganglia impairment (Weintraub et al., 2005). In post-mortem studies, a decrease in dopamine neurons in the ventral VTA was detected in depressed PD patients (Brown and Gershon, 1993). Additionally, in a PET imaging study, PD patients diagnosed with depression were observed to have decreased noradrenergic and dopaminergic innervation in emotion-related circuitry including the LC, anterior cingulate cortex, thalamus, amygdala and ventral striatum compared to both controls and PD patients without depression (Remy et al., 2005). While dopamine loss is observed in nonnigrostriatal pathways and can contribute to the formation of non-motor symptoms, the nigrostriatal pathway also has dopamine connections to the ventral striatum, and that pathway, along with the mesocortical and mesolimbic pathways, may play a role in reward (Wise, 2009). This has implications for the presence of depressive symptoms in PD such as anhedonia. If indeed the nigrostriatal pathway functions in the reward system, then the severe loss of dopamine neurons would almost inevitably cause dysfunction in the reward pathway as well.

\section{Parkinson's disease and stress}

Stress may play a role in the development of PD. The principle risk factor for PD is aging, which may also be associated with elevated levels of cortisol (Gould and Tanapat, 1999). Cortisol is also elevated in PD patients compared to healthy age-matched controls (Charlett et al., 1998). Acute treatment with levodopa can reduce plasma cortisol levels in PD patients (Müller et al., 2007), suggesting a connection between dopamine hypofunction and HPA axis hyperactivity. Stressful life events may also precipitate the development of PD. For example, prisoners of war had a much higher incident rate of PD development thirty-five years after release (Gibberd and Simmonds, 1980). Emotional stress can transiently increase motor symptoms (Macht et al., 2007), consistent with acute effects on nigrostriatal function. Appearance of the clinical PD symptoms during a stressful period may reflect damage to the nigrostriatal system that had been masked during the preclinical stage (Snyder et al., 1985). Loss of mesocortical dopamine neurons, which occurs in more advanced stages of PD, may result in the system becoming more vulnerable to stress, as dopamine release in the cortex 
inhibits stress-activated neurons in the nucleus accumbens (Finlay and Zigmond, 1997). Individuals with PD also have reduced hedonic responses after exposure to emotional stress, but stress did not affect the selected motor symptoms studied (Macht et al., 2007).

Glucocorticoids may have detrimental effects on PD neurodegeneration by accelerating disease progression (Kibel and Drenjančević-Perić, 2008; but see Ros-Bernal et al., 2011). Brain regions involved in motor control contain GRs in neurons and glia, with doublelabeling studies indicating co-localization with dopaminergic markers in the SNpc (Härfstrand et al., 1986; Ahima and Harlan, 1990). Stress not only affects the dopaminergic neurons in the mesocortical and mesolimbic pathways, but the nigrostriatal pathway as well (Keefe et al., 1990). Animals subjected to stress have increases in motor impairments resulting from dopamine loss (Snyder et al., 1985). Acute and chronic stress, as well as chronic corticosterone administration, impaired movement during the reaching test in animals and can be reversed by administration of anxiolytic compounds, suggesting both glucocorticoids and stress-associated anxiety can influence motor function (Metz et al., 2005). After lesioning, akinetic animals are still responsive to stress and can release a relatively increased amount of extracellular dopamine, supporting the idea that stress can modulate the injured nigrostriatal system (Keefe et al., 1990). Together, these studies indicate that stress can impinge on dopaminergic control of motor movements, with glucocorticoids possibly affecting the compensatory response to the damaged motor system (Metz, 2007). Interestingly, a recent study provided evidence that glucocorticoids acting via GRs are actually neuroprotective for injured nigrostriatal dopaminergic neurons (RosBernal et al., 2011). Thus, a complex picture is emerging regarding the precise role and function of stress hormones in PD.

Other forms of stress may influence nigrostriatal structure and function in animal models. Periodic maternal separation during early development increased motor behavior deficit and tyrosine hydroxylase loss within the striatum in rats treated with 6-hydroxydopamine (6OHDA) as adults (Pienaar et al., 2008). Maternal care disruption can have other long-term effects, such as the appearance of depressive symptoms in adult animals (Matthews and Robbins, 2003). Conversely, exercise can be neuroprotective in PD in both basic and clinical studies (Mabandla et al., 2010). Rats subjected to maternal separation during the neonatal stress hyporesponsive period of development and later allowed to voluntarily exercise showed reduced forelimb akinesia and forelimb-use asymmetry compared to non-exercised rats (Mabandla et al., 2010). Voluntary exercise also attenuated the increased neurodegeneration seen in lesioned animals exposed to mild prenatal stressors (Mabandla et al., 2009). However, in another study voluntarily exercised animals subjected to mild stressors as adults had a reduced protection against 6-OHDA lesions compared to nonstressed exercised animals (Howells et al., 2005). Thus, the timing and intensity of the stressors may affect the efficiency of exercise being neuroprotective.

In the striatum, stress increases the extracellular availability of glucocorticoids, glutamate, and dopamine (Smith et al., 2002). These all have the capacity to harm neurons separately and perhaps can even act in a synergistic manner to cause or exacerbate neuronal damage (Smith et al., 2002). Acute restraint stress given prior to administration of 6-OHDA increases behavioral and neurochemical deficits compared to animals that only received 6OHDA (Smith et al., 2002). Acute restraint stress also elevates nigrostriatal dopamine as well as factors involved in dopamine synthesis, including tetrahydrobiopterin and tyrosine hydroxylase (Kim et al., 2005). Excitatory amino acids such as glutamate can act on receptors within the $\mathrm{SNpc}$, increasing the striatal release of dopamine during stress exposure (Castro and Zigmond, 2001). As noted earlier, excitatory amino acids play a role in the neurodegeneration seen in the hippocampus after stress exposure (Magariños and McEwen, 1995b). The increase in dopamine caused by excitatory amino acids may increase the 
vulnerability of the neurons within the nigrostriatal pathway and produce a neurotoxic effect (Castro and Zigmond, 2001).

In addition to aberrant alterations in relevant neurotransmitters, inflammation is believed to be a major factor in the etiology of PD (Frank-Cannon et al., 2009; Qian et al., 2010). Inflammation results in lowered levels of BDNF within the SNpc of animals (Wu et al., 2011), and elevated levels of cytokines occur along with BDNF decreases in post-mortem PD brains (Nagatsu and Sawada, 2005). Loss of trophic signaling can increase neuronal loss in the nigrostriatal pathway (Baydyuk et al., 2011) and, as mentioned earlier, alteration of BDNF levels in key limbic regions may play a role in the development of depression (Nestler, 2002). Notably, chronic stress increases the pro-inflammatory environment in animal models of depression (You et al., 2011). Therefore, PD patients with depression and/ or chronic stress may experience a chronic neuroinflammatory environment perhaps linked to exacerbated PD pathology.

Both chronic stress and corticosterone administration result in increased motor impairment in lesioned animals (Smith et al., 2008). However, although this study noted an increase in Fluro-Jade labeled cells (indicating neurodegeneration) in the $\mathrm{SNpc}$, there was no reduction in numbers of tyrosine hydroxylase-positive cells (Smith et al., 2008). Interestingly, a recent report claims that lesions of the SNpc decrease cell proliferation within the subgranular layer of the hippocampal dentate gyrus, which chronic antidepressant treatment can attenuate (Suzuki et al., 2010). This suggests that not only can stress affect motor symptoms, but that damage to the nigrostriatal motor system could affect the control of the stress response.

\section{A combined depression/PD animal model}

In our own studies, we have developed an animal paradigm that combines the striatal 6OHDA lesion model of PD with the CVS-induced model of depression. With this model we are able to examine the combined effects that chronic stress and relatively progressive dopaminergic neuron loss can have on motor symptoms and nigral cell degeneration. We have observed that CVS worsens motor symptoms and increases neurodegeneration of dopaminergic neurons in the SNpc (Hemmerle et al., 2008, 2011). However, it appears that the stressors needs to be administered concomitant with the neurotoxin lesion (i.e. before and after) in order to do so, as administering the stressors only prior to or only following the lesion did not affect motor symptoms. The stress dysfunction occurring prior to the onset of motor symptoms and continuing after neuronal loss ultimately causes a worsening of the PD symptoms and accelerates nigral dopaminergic cell degeneration. Potential mechanisms underlying this CVS-induced exacerbation of experimental parkinsonism are currently being investigated.

\section{Conclusion}

Dysfunction of the HPA axis is well tied to depression symptomatology and plays a part in neuropsychiatric disorder development. What is not known at this juncture is the exact role stress and affective disorders may play in the development of neurodegenerative disorders such as PD. In humans, motor symptoms appear only after $70-80 \%$ of striatal dopaminergic content is lost, likely due to compensatory mechanisms in the remaining neurons. Preclinically, there may be manifestations of non-motor symptoms resulting from stress response dysfunction caused by the ongoing dopamine loss. The malfunction of the stress system could lead to an accelerated neurodegeneration in a positive feedback-type scenario. While acute and chronic stress do not appear to greatly affect the dopaminergic nigrostriatal pathway in healthy animals, little research has been done to determine the effects of stress on this system in the disease state of PD in both humans and animals models. Additionally, 
stress effects on the mesolimbic and mesocortical pathways may also have a part in the development of depression in PD. The development of new animal models will help address the relationship of stress-induced depression and PD dysfunction and hopefully generate new therapies to treat both mood and motor aspects of the disorder.

\section{Acknowledgments}

The work was supported by NIH grant NS060114, Udall Parkinson's Disease Centers of Excellence grant NS058830, and by grants from the Sunflower Revolution/University of Cincinnati Neuroscience Institute, the Gardner Family Center for Parkinson's Disease and Movement Disorders, and the Parkinson's Disease Support Network of Ohio, Kentucky and Indiana. AMH was supported by the Morris Braun Foundation and a University Research Council Fellowship.

\section{References}

Aarsland D, Marsh L, Schrag A. Neuropsychiatric symptoms in Parkinson's disease. Mov Disord. 2009; 24:2175-2186. [PubMed: 19768724]

Abercrombie ED, Keefe KA, DiFrischia DS, Zigmond MJ. Differential effect of stress on in vivo dopamine release in striatum, nucleus accumbens, and medial frontal cortex. J Neurochem. 1989; 52:1655-1658. [PubMed: 2709017]

Adzic M, Djordjevic J, Djordjevic A, Niciforovic A, Demonacos C, Radojcic M, Krstic-Demonacos M. Acute or chronic stress induce cell compartment-specific phosphorylation of glucocorticoid receptor and alter its transcriptional activity in Wistar rat brain. J Endocrinol. 2009; 202:87-97. [PubMed: 19406955]

Ahima RS, Harlan RE. Charting of type II glucocorticoid receptor-like immunoreactivity in the rat central nervous system. Neuroscience. 1990; 39:579-604. [PubMed: 1711170]

Ahmad A, Rasheed N, Banu N, Palit G. Alterations in monoamine levels and oxidative systems in frontal cortex, striatum, and hippocampus of the rat brain during chronic unpredictable stress. Stress. 2010; 13:355-364. [PubMed: 20536337]

Arranz B, Blennow K, Eriksson A, Mansson JE, Marcusson J. Serotonergic, noradrenergic, and dopaminergic measures in suicide brains. Biol Psychiatry. 1997; 41:1000-1009. [PubMed: 9129780]

Bachis A, Cruz MI, Nosheny RL, Mocchetti I. Chronic unpredictable stress promotes neuronal apoptosis in the cerebral cortex. Neurosci Lett. 2008; 442:104-108. [PubMed: 18621098]

Barone P, Lamb J, Ellis A, Clarke Z. Sumanirole versus placebo or ropinirole for the adjunctive treatment of patients with advanced Parkinson's disease. Mov Disord. 2007; 22:483-489. [PubMed: 17115380]

Baydyuk M, Nguyen MT, Xu B. Chronic deprivation of TrkB signaling leads to selective late-onset nigrostriatal dopaminergic degeneration. Exp Neurol. 2011; 228:118-125. [PubMed: 21192928]

Bohnen NI, Kaufer DI, Hendrickson R, Constantine GM, Mathis CA, Moore RY. Cortical cholinergic denervation is associated with depressive symptoms in Parkinson's disease and parkinsonian dementia. J Neurol Neurosurg Psychiatry. 2007; 78:641-643. [PubMed: 17507447]

Boileau I, Warsh JJ, Guttman M, Saint-Cyr JA, McCluskey T, Rusjan P, Houle S, Wilson AA, Meyer JH, Kish SJ. Elevated serotonin transporter binding in depressed patients with Parkinson's disease: a preliminary PET study with [11C]DASB. Mov Disord. 2008; 23:1776-1780. [PubMed: 18661545]

Brown AS, Gershon S. Dopamine and depression. J Neural Transm Gen Sect. 1993; 91:75-109. [PubMed: 8099801]

Brown R, Jahanshahi M. Depression in Parkinson's disease: a psychosocial viewpoint. Adv Neurol. 1995; 65:61-84. [PubMed: 7872153]

Brown J, Cooper-Kuhn CM, Kempermann G, Van Praag H, Winkler J, Gage FH, Kuhn HG. Enriched environment and physical activity stimulate hippocampal but not olfactory bulb neurogenesis. Eur J Neurosci. 2003; 17:2042-2046. [PubMed: 12786970]

Cardoso EF, Maia FM, Fregni F, Myczkowski ML, Melo LM, Sato JR, Marcolin MA, Rigonatti SP, Cruz AC Jr, Barbosa ER, Amaro E Jr. Depression in Parkinson's disease: convergence from 
voxel-based morphometry and functional magnetic resonance imaging in the limbic thalamus. Neuroimage. 2009; 47:467-472. [PubMed: 19398020]

Castro SL, Zigmond MJ. Stress-induced increase in extracellular dopamine in striatum: role of glutamatergic action via N-methyl-D-aspartate receptors in substantia nigra. Brain Res. 2001; 901:47-54. [PubMed: 11368949]

Cerqueira JJ, Pego JM, Taipa R, Bessa JM, Almeida OF, Sousa N. Morphological correlates of corticosteroid-induced changes in prefrontal cortex-dependent behaviors. J Neurosci. 2005; 25:7792-7800. [PubMed: 16120780]

Chan-Palay V, Asan E. Quantitation of catecholamine neurons in the locus coeruleus in human brains of normal young and older adults and in depression. J Comp Neurol. 1989a; 287:357-372. [PubMed: 2570793]

Chan-Palay V, Asan E. Alterations in catecholamine neurons of the locus coeruleus in senile dementia of the Alzheimer type and in Parkinson's disease with and without dementia and depression. J Comp Neurol. 1989b; 287:373-392. [PubMed: 2570794]

Charlett A, Dobbs RJ, Purkiss AG, Wright DJ, Peterson DW, Weller C, Dobbs SM. Cortisol is higher in parkinsonism and associated with gait deficit. Acta Neurol Scand. 1998; 97:77-85. [PubMed: 9517856]

Chaudhuri KR, Schapira AH. Non-motor symptoms of Parkinson's disease: dopaminergic pathophysiology and treatment. Lancet Neurol. 2009; 8:464-474. [PubMed: 19375664]

Cummings JL. Depression and Parkinson's disease: a review. Am J Psychiatry. 1992; 149:443-454. [PubMed: 1372794]

Dias-Ferreira E, Sousa JC, Melo I, Morgado P, Mesquita AR, Cerqueira JJ, Costa RM, Sousa N. Chronic stress causes frontostriatal reorganization and affects decision-making. Science. 2009; 325:621-625. [PubMed: 19644122]

Duman RS. Pathophysiology of depression: the concept of synaptic plasticity. Eur Psychiatry. 2002; 17(Suppl 3):306-310. [PubMed: 15177086]

Duman RS. Role of neurotrophic factors in the etiology and treatment of mood disorders. Neuromolecular Med. 2004a; 5:11-25. [PubMed: 15001809]

Duman RS. Depression: a case of neuronal life and death? Biol Psychiatry. 2004b; 56:140-145. [PubMed: 15271581]

Duman RS, Monteggia LM. A neurotrophic model for stress-related mood disorders. Biol Psychiatry. 2006; 59:1116-1127. [PubMed: 16631126]

Duval F, Mokrani MC, Monreal-Ortiz JA, Fattah S, Champeval C, Schulz P, Macher JP. Cortisol hypersecretion in unipolar major depression with melancholic and psychotic features: dopaminergic, noradrenergic and thyroid correlates. Psychoneuroendocrinol. 2006; 31:876-888.

Finlay JM, Zigmond MJ. The effects of stress on central dopaminergic neurons: possible clinical implications. Neurochem Res. 1997; 22:1387-1394. [PubMed: 9355111]

Forlenza MJ, Miller GE. Increased serum levels of 8-hydroxy-2'-deoxyguanosine in clinical depression. Psychosom Med. 2006; 68:1-7. [PubMed: 16449405]

Fox SH, Chuang R, Brotchie JM. Serotonin and Parkinson's disease: On movement, mood, and madness. Mov Disord. 2009; 24:1255-1266. [PubMed: 19412960]

Frank-Cannon TC, Alto LT, McAlpine FE, Tansey MG. Does neuroinflammation fan the flame in neurodegenerative diseases? Mol Neurodegener. 2009; 4:47. [PubMed: 19917131]

Fuchs E, Flügge G. Stress, glucocorticoids and structural plasticity of the hippocampus. Neurosci Biobehav Rev. 1998; 23:295-300. [PubMed: 9884123]

Gibberd FB, Simmonds JP. Neurological disease in ex-Far-East prisoners of war. Lancet. 1980; 2:135137. [PubMed: 6105303]

Giladi N, Treves TA, Paleacu D, Shabtai H, Kandinov B, Simon ES, Korczyn AD. Risk factors for dementia, depression and psychosis in long-standing Parkinson's disease. J Neural Transm. 2000; 107:59-71. [PubMed: 10809404]

Gold PW, Goodwin FK, Chrousos GP. Clinical and biochemical manifestations of depression. Relation to the neurobiology of stress. N Engl J Med. 1988; 319:413-420. [PubMed: 3041279] 
Gold PW, Chrousos GP. Organization of the stress system and its dysregulation in melancholic and atypical depression: high vs low CRH/NE states. Mol Psychiatry. 2002; 7:254-275. [PubMed: 11920153]

Gould E, Woolley CS, Cameron HA, Daniels DC, McEwen BS. Adrenal steroids regulate postnatal development of the rat dentate gyrus: II. Effects of glucocorticoids and mineralocorticoids on cell birth. J Comp Neurol. 1991; 313:486-493. [PubMed: 1770172]

Gould E, Tanapat P. Stress and hippocampal neurogenesis. Biol Psychiatry. 1999; 46:1472-1479. [PubMed: 10599477]

Gresch PJ, Sved AF, Zigmond MJ, Finlay JM. Stress-induced sensitization of dopamine and norepinephrine efflux in medial prefrontal cortex of the rat. J Neurochem. 1994; 63:575-583. [PubMed: 8035182]

Grippo AJ, Francis J, Beltz TG, Felder RB, Johnson AK. Neuroendocrine and cytokine profile of chronic mild stress-induced anhedonia. Physiol Behav. 2005; 84:697-706. [PubMed: 15885245]

Härfstrand A, Fuxe K, Cintra A, Agnati LF, Zini I, Wikström AC, Okret S, Yu ZY, Goldstein M, Steinbusch H, Verhofstad A, Gustafsson J-Å. Glucocorticoid receptor immunoreactivity in monoaminergic neurons of rat brain. Proc Natl Acad Sci USA. 1986; 83:9779-9783. [PubMed: 2879285]

Hemmerle AM, Dickerson JW, Packard BA, Jones KR, Dolgas CM, Herman JP, Seroogy KB. Temporal effects of chronic variable stress on dopaminergic cell degeneration and motor deficits in a partial lesion model of Parkinson's disease. Soc Neurosci Abstr \# 741.13. 2008

Hemmerle AM, Kyser TL, Schmeltzer SN, Lundgren KH, Herman JP, Seroogy KB. Do glucocorticoids mediate chronic stress-induced exacerbation of neurodegeneration and behavioral dysfunction in experimental parkinsonism? Soc Neurosci Abstr Abstr \# 883.06. 2011

Herman JP. Regulation of adrenocorticosteroid receptor mRNA expression in the central nervous system. Cell Mol Neurobiol. 1993; 13:349-372. [PubMed: 8252607]

Herman JP, Cullinan WE. Neurocircuitry of stress: central control of the hypothalamo-pituitaryadrenocortical axis. Trends Neurosci. 1997; 20:78-84. [PubMed: 9023876]

Herman JP, Adams D, Prewitt C. Regulatory changes in neuroendocrine stress- integrative circuitry produced by a variable stress paradigm. Neuroendocrinology. 1995; 61:180-190. [PubMed: 7753337]

Hesse S, Meyer PM, Strecker K, Barthel H, Wegner F, Oehlwein C, Isaias IU, Schwarz J, Sabri O. Monoamine transporter availability in Parkinson's disease patients with or without depression. Eur J Nucl Med Mol Imaging. 2009; 36:428-435. [PubMed: 19037640]

Heuser IJ, Chase TN, Mouradian MM. The limbic-hypothalamic-pituitary-adrenal axis in Huntington's disease. Biol Psychiatry. 1991; 30:943-952. [PubMed: 1660734]

Howells FM, Russell VA, Mabandla MV, Kellaway LA. Stress reduces the neuroprotective effect of exercise in a rat model for Parkinson's disease. Behav Brain Res. 2005; 165:210-220. [PubMed: 16159673]

Imperato A, Puglisi-Allegra S, Zocchi A, Scrocco MG, Casolini P, Angelucci L. Stress activation of limbic and cortical dopamine release is prevented by ICS $205-930$ but not by diazepam. Eur J Pharmacol. 1990; 175:211-214. [PubMed: 2311655]

Issa AM, Rowe W, Gauthier S, Meaney MJ. Hypothalamic-pituitary-adrenal activity in aged, cognitively impaired and cognitively unimpaired rats. J Neurosci. 1990; 10:3247-3254. [PubMed: 2170594]

Kanner AM. Is major depression a neurologic disorder with psychiatric symptoms? Epilepsy Behav. 2004; 5:636-644. [PubMed: 15380113]

Kathol RG, Jaeckle RS, Lopez JF, Meller WH. Pathophysiology of HPA axis abnormalities in patients with major depression: an update. Am J Psychiatry. 1989; 146:311-317. [PubMed: 2645793]

Katz RJ, Roth KA, Carroll BJ. Acute and chronic stress effects on open field activity in the rat: implications for a model of depression. Neurosci Biobehav Rev. 1981; 5:247-251. [PubMed: 7196554]

Keefe KA, Stricker EM, Zigmond MJ, Abercrombie ED. Environmental stress increases extracellular dopamine in striatum of 6-hydroxydopamine-treated rats: in vivo microdialysis studies. Brain Res. 1990; 527:350-353. [PubMed: 2123730] 
Kendler KS, Karkowski LM, Prescott CA. Causal relationship between stressful life events and the onset of major depression. Am J Psychiatry. 1999; 156:837-841. [PubMed: 10360120]

Kessler RC, Berglund P, Demler O, Jin R, Koretz D, Merikangas KR, Rush AJ, Walters EE, Wang PS. The epidemiology of major depressive disorder: results from the National Comorbidity Survey Replication (NCS-R). J Am Med Assoc. 2003; 289:3095-3105.

Kibel A, Drenjancevic-Peric I. Impact of glucocorticoids and chronic stress on progression of Parkinson's disease. Med Hypotheses. 2008; 71:952-956. [PubMed: 18718724]

Kim ST, Choi JH, Chang JW, Kim SW, Hwang O. Immobilization stress causes increases in tetrahydrobiopterin, dopamine, and neuromelanin and oxidative damage in the nigrostriatal system. J Neurochem. 2005; 95:89-98. [PubMed: 16181415]

Kosten TA, Galloway MP, Duman RS, Russell DS, D'Sa C. Repeated unpredictable stress and antidepressants differentially regulate expression of the bcl-2 family of apoptotic genes in rat cortical, hippocampal, and limbic brain structures. Neuropsychopharmacology. 2008; 33:15451558. [PubMed: 17700647]

Kostić VS, Agosta F, Petrović I, Galantucci S, Spica V, Jecmenica-Lukic M, Filippi M. Regional patterns of brain tissue loss associated with depression in Parkinson disease. Neurology. 2010; 75:857-863. [PubMed: 20686125]

Kubera M, Obuchowicz E, Goehler L, Brzeszcz J, Maes M. In animal models, psychosocial stressinduced (neuro)inflammation, apoptosis and reduced neurogenesis are associated to the onset of depression. Prog Neuropsychopharmacol Biol Psychiatry. 2011; 35:744-759. [PubMed: 20828592]

Kummer A, Cardoso F, Teixeira AL. Suicidal ideation in Parkinson's disease. CNS Spectr. 2009; 14:431-436. [PubMed: 19890237]

Kuopio AM, Marttila RJ, Helenius H, Toivonen M, Rinne UK. The quality of life in Parkinson's disease. Mov Disord. 2000; 15:216-223. [PubMed: 10752569]

Landfield PW, Eldridge JC. Increased affinity of type II corticosteroid binding in aged rat hippocampus. Exp Neurol. 1989; 106:110-113. [PubMed: 2792294]

Lavretsky H, Roybal DJ, Ballmaier M, Toga AW, Kumar A. Antidepressant exposure may protect against decrement in frontal gray matter volumes in geriatric depression. J Clin Psychiatry. 2005; 66:964-967. [PubMed: 16086609]

Leentjens AF, Van den Akker M, Metsemakers JF, Lousberg R, Verhey FR. Higher incidence of depression preceding the onset of Parkinson's disease: a register study. Mov Disord. 2003a; 18:414-418. [PubMed: 12671948]

Leentjens AF, Vreeling FW, Luijckx GJ, Verhey FR. SSRIs in the treatment of depression in Parkinson's disease. Int J Geriatr Psychiatry. 2003b; 18:552-554. [PubMed: 12789682]

Leentjens AF. Depression in Parkinson's disease: conceptual issues and clinical challenges. J Geriatr Psychiatry Neurol. 2004; 17:120-126. [PubMed: 15312275]

Leentjens AF. The role of dopamine agonists in the treatment of depression in patients with Parkinson's disease: a systematic review. Drugs. 2011; 71:273-286. [PubMed: 21319866]

Lemke MR. Depressive symptoms in Parkinson's disease. Eur J Neurol Suppl. 2008; 1:21-25.

Li W, Liu J, Skidmore F, Liu Y, Tian J, Li K. White matter microstructure changes in the thalamus in Parkinson disease with depression: A diffusion tensor MR imaging study. AJNR Am J Neuroradiol. 2010; 31:1861-1866. [PubMed: 20705702]

Lieberman A. Depression in Parkinson's disease -- a review. Acta Neurol Scand. 2006; 113:1-8. [PubMed: 16367891]

Lucca G, Comim CM, Valvassori SS, Reus GZ, Vuolo F, Petronilho F, Dal-Pizzol F, Gavioli EC, Quevedo J. Effects of chronic mild stress on the oxidative parameters in the rat brain. Neurochem Int. 2009a; 54:358-362. [PubMed: 19171172]

Lucca G, Comim CM, Valvassori SS, Réus GZ, Vuolo F, Petronilho F, Gavioli EC, Dal-Pizzol F, Quevedo J. Increased oxidative stress in submitochondrial particles into the brain of rats submitted to the chronic mild stress paradigm. J Psychiatr Res. 2009b; 43:864-869. [PubMed: 19100996]

Mabandla MV, Russell VA. Voluntary exercise reduces the neurotoxic effects of 6-hydroxydopamine in maternally separated rats. Behav Brain Res. 2010; 211:16-22. [PubMed: 20206210] 
Mabandla MV, Kellaway LA, Daniels WM, Russell VA. Effect of exercise on dopamine neuron survival in prenatally stressed rats. Metab Brain Dis. 2009; 24:525-539. [PubMed: 19844780]

Macht M, Brandstetter S, Ellgring H. Stress affects hedonic responses but not reaching-grasping in Parkinson's disease. Behav Brain Res. 2007; 177:171-174. [PubMed: 17129618]

Maes M, Yirmyia R, Noraberg J, Brene S, Hibbeln J, Perini G, Kubera M, Bob P, Lerer B, Maj M. The inflammatory \& neurodegenerative (I\&ND) hypothesis of depression: leads for future research and new drug developments in depression. Metab Brain Dis. 2009; 24:27-53. [PubMed: 19085093]

Magariños AM, McEwen BS. Stress-induced atrophy of apical dendrites of hippocampal CA3c neurons: involvement of glucocorticoid secretion and excitatory amino acid receptors. Neuroscience. 1995a; 69:89-98.

Magariños AM, McEwen BS. Stress-induced atrophy of apical dendrites of hippocampal CA3c neurons: comparison of stressors. Neuroscience. 1995b; 69:83-88.

Malberg JE, Eisch AJ, Nestler EJ, Duman RS. Chronic antidepressant treatment increases neurogenesis in adult rat hippocampus. J Neurosci. 2000; 20:9104-9110. [PubMed: 11124987]

Matthews K, Robbins TW. Early experience as a determinant of adult behavioural responses to reward: the effects of repeated maternal separation in the rat. Neurosci Biobehav Rev. 2003; 27:45-55. [PubMed: 12732222]

Mayberg HS, Lozano AM, Voon V, McNeely HE, Seminowicz D, Hamani C, Schwalb JM, Kennedy SH. Deep brain stimulation for treatment-resistant depression. Neuron. 2005; 45:651-660. [PubMed: 15748841]

Mayeux R, Stern Y, Cote L, Williams JB. Altered serotonin metabolism in depressed patients with Parkinson's disease. Neurology. 1984; 34:642-646. [PubMed: 6200801]

McDonald WM, Richard IH, DeLong MR. Prevalence, etiology, and treatment of depression in Parkinson's disease. Biol Psychiatry. 2003; 54:363-375. [PubMed: 12893111]

McGonagle KA, Kessler RC. Chronic stress, acute stress, and depressive symptoms. Am J Community Psychol. 1990; 18:681-706. [PubMed: 2075897]

Menza MA, Mark MH. Parkinson's disease and depression: the relationship to disability and personality. J Neuropsychiatry Clin Neurosci. 1994; 6:165-169. [PubMed: 8044039]

Metz GA. Stress as a modulator of motor system function and pathology. Rev Neurosci. 2007; 18:209_ 222. [PubMed: 18019607]

Metz GA, Jadavji NM, Smith LK. Modulation of motor function by stress: a novel concept of the effects of stress and corticosterone on behavior. Eur J Neurosci. 2005; 22:1190-1200. [PubMed: 16176362]

Meyer PM, Strecker K, Kendziorra K, Becker G, Hesse S, Woelpl D, Hensel A, Patt M, Sorger D, Wegner F, Lobsien D, Barthel H, Brust P, Gertz HJ, Sabri O, Schwarz J. Reduced alpha4beta2*nicotinic acetylcholine receptor binding and its relationship to mild cognitive and depressive symptoms in Parkinson disease. Arch Gen Psychiatry. 2009; 66:866-877. [PubMed: 19652126]

Mitra R, Sapolsky RM. Acute corticosterone treatment is sufficient to induce anxiety and amygdaloid dendritic hypertrophy. Proc Natl Acad Sci USA. 2008; 105:5573-5578. [PubMed: 18391224]

Mizoguchi K, Shoji H, Ikeda R, Tanaka Y, Tabira T. Persistent depressive state after chronic stress in rats is accompanied by HPA axis dysregulation and reduced prefrontal dopaminergic neurotransmission. Pharmacol Biochem Behav. 2008; 91:170-175. [PubMed: 18675292]

Müller T, Welnic J, Muhlack S. Acute levodopa administration reduces cortisol release in patients with Parkinson's disease. J Neural Transm. 2007; 114:347-350. [PubMed: 16932991]

Murphy EK, Spencer RL, Sipe KJ, Herman JP. Decrements in nuclear glucocorticoid receptor (GR) protein levels and DNA binding in aged rat hippocampus. Endocrinology. 2002; 143:1362-1370. [PubMed: 11897693]

Nagatsu T, Sawada M. Inflammatory process in Parkinson's disease: role for cytokines. Curr Pharm Des. 2005; 11:999-1016. [PubMed: 15777250]

Nemeroff CB, Widerlov E, Bissette G, Walleus H, Karlsson I, Eklund K, Kilts CD, Loosen PT, Vale W. Elevated concentrations of CSF corticotropin-releasing factor-like immunoreactivity in depressed patients. Science. 1984; 226:1342-1344. [PubMed: 6334362]

Nestler EJ, Barrot M, DiLeone RJ, Eisch AJ, Gold SJ, Monteggia LM. Neurobiology of depression. Neuron. 2002; 34:13-25. [PubMed: 11931738] 
Nibuya M, Morinobu S, Duman RS. Regulation of BDNF and trkB mRNA in rat brain by chronic electroconvulsive seizure and antidepressant drug treatments. J Neurosci. 1995; 15:7539-7547. [PubMed: 7472505]

Nilsson FM, Kessing LV, Bolwig TG. Increased risk of developing Parkinson's disease for patients with major affective disorder: a register study. Acta Psychiatr Scand. 2001; 104:380-386. [PubMed: 11722320]

Pålhagen SE, Carlsson M, Curman E, Walinder J, Granerus AK. Depressive illness in Parkinson's disease--indication of a more advanced and widespread neurodegenerative process? Acta Neurol Scand. 2008; 117:295-304. [PubMed: 18279483]

Pani L, Porcella A, Gessa GL. The role of stress in the pathophysiology of the dopaminergic system. Mol Psychiatry. 2000; 5:14-21. [PubMed: 10673764]

Papapetropoulos S, Ellul J, Argyriou AA, Chroni E, Lekka NP. The effect of depression on motor function and disease severity of Parkinson's disease. Clin Neurol Neurosurg. 2006; 108:465-469. [PubMed: 16150537]

Papp M, Willner P, Muscat R. Behavioural sensitization to a dopamine agonist is associated with reversal of stress-induced anhedonia. Psychopharmacology (Berl). 1993; 110:159-164. [PubMed: 7870877]

Patacchioli FR, Monnazzi P, Scontrini A, Tremante E, Caridi I, Brunetti E, Buttarelli FR, Pontieri FE. Adrenal dysregulation in amyotrophic lateral sclerosis. J Endocrinol Invest. 2003; 26:RC23-25. [PubMed: 15055464]

Pienaar IS, Kellaway LA, Russell VA, Smith AD, Stein DJ, Zigmond MJ, Daniels WM. Maternal separation exaggerates the toxic effects of 6-hydroxydopamine in rats: implications for neurodegenerative disorders. Stress. 2008; 11:448-456. [PubMed: 18609296]

Pham K, Nacher J, Hof PR, McEwen BS. Repeated restraint stress suppresses neurogenesis and induces biphasic PSA-NCAM expression in the adult rat dentate gyrus. Eur J Neurosci. 2003; 17:879-886. [PubMed: 12603278]

Qian L, Flood PM, Hong JS. Neuroinflammation is a key player in Parkinson's disease and a prime target for therapy. J Neural Transm. 2010; 117:971-979. [PubMed: 20571837]

Radley JJ, Sisti HM, Hao J, Rocher AB, McCall T, Hof PR, McEwen BS, Morrison JH. Chronic behavioral stress induces apical dendritic reorganization in pyramidal neurons of the medial prefrontal cortex. Neuroscience. 2004; 125:1-6. [PubMed: 15051139]

Rasheed N, Ahmad A, Pandey CP, Chaturvedi RK, Lohani M, Palit G. Differential response of central dopaminergic system in acute and chronic unpredictable stress models in rats. Neurochem Res. 2010; 35:22-32. [PubMed: 19568932]

Reijnders JS, Scholtissen B, Weber WE, Aalten P, Verhey FR, Leentjens AF. Neuroanatomical correlates of apathy in Parkinson's disease: A magnetic resonance imaging study using voxelbased morphometry. Mov Disord. 2010; 25:2318-2325. [PubMed: 20669264]

Remy P, Doder M, Lees A, Turjanski N, Brooks D. Depression in Parkinson's disease: loss of dopamine and noradrenaline innervation in the limbic system. Brain. 2005; 128:1314-1322. [PubMed: 15716302]

Richard IH, Kurlan R. A survey of antidepressant drug use in Parkinson's disease. Parkinson Study Group. Neurology. 1997; 49:1168-1170. [PubMed: 9339713]

Richard IH. Depression and apathy in Parkinson's disease. Curr Neurol Neurosci Rep. 2007; 7:295301. [PubMed: 17618535]

Riedel O, Klotsche J, Spottke A, Deuschl G, Förstl H, Henn F, Heuser I, Oertel W, Reichmann H, Riederer P, Trenkwalder C, Dodel R, Wittchen HU. Frequency of dementia, depression, and other neuropsychiatric symptoms in 1,449 outpatients with Parkinson's disease. J Neurol. 2010; 257:1073-1082. [PubMed: 20140443]

Ros-Bernal F, Hunot S, Herrero MT, Parnadeau S, Corvol JC, Lu L, Alvarez-Fischer D, Carrillo-de Sauvage MA, Saurini F, Coussieu C, Kinugawa K, Prigent A, Höglinger G, Hamon M, Tronche F, Hirsch EC, Vyas S. Microglial glucocorticoid receptors play a pivotal role in regulating dopaminergic neurodegeneration in parkinsonism. Proc Natl Acad Sci USA. 2011; 108:66326637. [PubMed: 21467220] 
Salvadore G, Nugent AC, Lemaitre H, Luckenbaugh DA, Tinsley R, Cannon DM, Neumeister A, Zarate CA Jr, Drevets WC. Prefrontal cortical abnormalities in currently depressed versus currently remitted patients with major depressive disorder. Neuroimage. 2011; 54:2643-2651. [PubMed: 21073959]

Sapolsky RM, Krey LC, McEwen BS. Corticosterone receptors decline in a site-specific manner in the aged rat brain. Brain Res. 1983; 289:235-240. [PubMed: 6661643]

Sapolsky RM, Krey LC, McEwen BS. Prolonged glucocorticoid exposure reduces hippocampal neuron number: implications for aging. J Neurosci. 1985; 5:1222-1227. [PubMed: 3998818]

Sapolsky RM, Packan DR, Vale WW. Glucocorticoid toxicity in the hippocampus: in vitro demonstration. Brain Res. 1988; 453:367-371. [PubMed: 3401775]

Sapolsky RM. The physiological relevance of glucocorticoid endangerment of the hippocampus. Ann NY Acad Sci. 1994; 746:294-304. [PubMed: 7825884]

Schaaf MJ, Hoetelmans RW, de Kloet ER, Vreugdenhil E. Corticosterone regulates expression of BDNF and trkB but not NT-3 and trkC mRNA in the rat hippocampus. J Neurosci Res. 1997; 48:334-341. [PubMed: 9169859]

Schaaf MJ, de Jong J, de Kloet ER, Vreugdenhil E. Downregulation of BDNF mRNA and protein in the rat hippocampus by corticosterone. Brain Res. 1998; 813:112-120. [PubMed: 9824681]

Schrag A, Hovris A, Morley D, Quinn N, Jahanshahi M. Young- versus older-onset Parkinson's disease: impact of disease and psychosocial consequences. Mov Disord. 2003; 18:1250-1256. [PubMed: 14639664]

Schrag A. Quality of life and depression in Parkinson's disease. J Neurol Sci. 2006; 248:151-157. [PubMed: 16797028]

Serra-Mestres J, Ring HA. Evidence supporting a cognitive model of depression in Parkinson's disease. J Nerv Ment Dis. 2002; 190:407-410. [PubMed: 12080213]

Sheline YI. Neuroimaging studies of mood disorder effects on the brain. Biol Psychiatry. 2003; 54:338-352. [PubMed: 12893109]

Sheline YI, Wang PW, Gado MH, Csernansky JG, Vannier MW. Hippocampal atrophy in recurrent major depression. Proc Natl Acad Sci USA. 1996; 93:3908-3913. [PubMed: 8632988]

Smith AD, Castro SL, Zigmond MJ. Stress-induced Parkinson's disease: a working hypothesis. Physiol Behav. 2002; 77:527-531. [PubMed: 12526994]

Smith LK, Jadavji NM, Colwell KL, Katrina Perehudoff S, Metz GA. Stress accelerates neural degeneration and exaggerates motor symptoms in a rat model of Parkinson's disease. Eur J Neurosci. 2008; 27:2133-2146. [PubMed: 18412632]

Smith MA, Makino S, Altemus M, Michelson D, Hong SK, Kvetnansky R, Post RM. Stress and antidepressants differentially regulate neurotrophin $3 \mathrm{mRNA}$ expression in the locus coeruleus. Proc Natl Acad Sci USA. 1995; 92:8788-8792. [PubMed: 7568018]

Snyder AM, Stricker EM, Zigmond MJ. Stress-induced neurological impairments in an animal model of parkinsonism. Ann Neurol. 1985; 18:544-551. [PubMed: 3935041]

Song DK, Choe B, Bae JH, Park WK, Han IS, Ho WK, Earm YE. Brain-derived neurotrophic factor rapidly potentiates synaptic transmission through NMDA, but suppresses it through non-NMDA receptors in rat hippocampal neuron. Brain Res. 1998; 799:176-179. [PubMed: 9666119]

Steffens DC, Fisher GG, Langa KM, Potter GG, Plassman BL. Prevalence of depression among older Americans: the Aging, Demographics and Memory Study. Int Psychogeriatr. 2009; 21:879-888. [PubMed: 19519984]

Sun XL, Liu Y, Dai T, Ding JH, Hu G. Uncoupling protein 2 knockout exacerbates depression-like behaviors in mice via enhancing inflammatory response. Neuroscience. 2011; 192:507-514. [PubMed: 21729739]

Suzuki K, Okada K, Wakuda T, Shinmura C, Kameno Y, Iwata K, Takahashi T, Suda S, Matsuzaki H, Iwata Y, Hashimoto K, Mori N. Destruction of dopaminergic neurons in the midbrain by 6hydroxydopamine decreases hippocampal cell proliferation in rats: reversal by fluoxetine. PLoS One. 2010; 5:e9260. [PubMed: 20174647]

Swaab DF, Bao AM, Lucassen PJ. The stress system in the human brain in depression and neurodegeneration. Ageing Res Rev. 2005; 4:141-194. [PubMed: 15996533] 
Tagliari B, dos Santos TM, Cunha AA, Lima DD, Delwing D, Sitta A, Vargas CR, Dalmaz C, Wyse AT. Chronic variable stress induces oxidative stress and decreases butyrylcholinesterase activity in blood of rats. J Neural Transm. 2010; 117:1067-1076. [PubMed: 20686907]

Tang Y, Wang F, Xie G, Liu J, Li L, Su L, Liu Y, Hu X, He Z, Blumberg HP. Reduced ventral anterior cingulate and amygdala volumes in medication-naïve females with major depressive disorder: A voxel-based morphometric magnetic resonance imaging study. Psychiatry Res. 2007; 156:83-86. [PubMed: 17825533]

Ulrich-Lai YM, Herman JP. Neural regulation of endocrine and autonomic stress responses. Nat Rev Neurosci. 2009; 10:397-409. [PubMed: 19469025]

Van Craenenbroeck K, De Bosscher K, Vanden Berghe W, Vanhoenacker P, Haegeman G. Role of glucocorticoids in dopamine-related neuropsychiatric disorders. Mol Cell Endocrinol. 2005; 245:10-22. [PubMed: 16310935]

Vyas A, Mitra R, Shankaranarayana Rao BS, Chattarji S. Chronic stress induces contrasting patterns of dendritic remodeling in hippocampal and amygdaloid neurons. J Neurosci. 2002; 22:6810-6818. [PubMed: 12151561]

Wang SS, Yan XB, Hofman MA, Swaab DF, Zhou JN. Increased expression level of corticotropinreleasing hormone in the amygdala and in the hypothalamus in rats exposed to chronic unpredictable mild stress. Neurosci Bull. 2010; 26:297-303. [PubMed: 20651811]

Weintraub D, Newberg AB, Cary MS, Siderowf AD, Moberg PJ, Kleiner-Fisman G, Duda JE, Stern MB, Mozley D, Katz IR. Striatal dopamine transporter imaging correlates with anxiety and depression symptoms in Parkinson's disease. J Nucl Med. 2005; 46:227-232. [PubMed: 15695780]

Weintraub D, Comella CL, Horn S. Parkinson's disease--Part 1: Pathophysiology, symptoms, burden, diagnosis, and assessment. Am J Manag Care. 2008a; 14:S40-48. [PubMed: 18402507]

Weintraub D, Comella CL, Horn S. Parkinson's disease--Part 3: Neuropsychiatric symptoms. Am J Manag Care. 2008b; 14:S59-69. [PubMed: 18402509]

Wellman CL. Dendritic reorganization in pyramidal neurons in medial prefrontal cortex after chronic corticosterone administration. J Neurobiol. 2001; 49:245-253. [PubMed: 11745662]

Willner P. Chronic mild stress (CMS) revisited: consistency and behavioural- neurobiological concordance in the effects of CMS. Neuropsychobiology. 2005; 52:90-110. [PubMed: 16037678]

Wise RA. Roles for nigrostriatal--not just mesocorticolimbic--dopamine in reward and addiction. Trends Neurosci. 2009; 32:517-524. [PubMed: 19758714]

Wu SY, Wang TF, Yu L, Jen CJ, Chuang JI, Wu FS, Wu CW, Kuo YM. Running exercise protects the substantia nigra dopaminergic neurons against inflammation-induced degeneration via the activation of BDNF signaling pathway. Brain Behav Immun. 2011; 25:135-146. [PubMed: 20851176]

Yamamoto M. Depression in Parkinson's disease: its prevalence, diagnosis, and neurochemical background. J Neurol. 2001; 248(Suppl 3):III5-11. [PubMed: 11697689]

Yang D, Liu X, Zhang R, Cheng K, Mu J, Fang L, Xie P. Increased apoptosis and different regulation of pro-apoptosis protein bax and anti-apoptosisprotein bcl-2 in the olfactory bulb of a rat model of depression. Neurosci Lett. 201110.1016/j.neulet.2011.08.046

Yehuda R, Yang RK, Buchsbaum MS, Golier JA. Alterations in cortisol negative feedback inhibition as examined using the ACTH response to cortisol administration in PTSD. Psychoneuroendocrinol. 2006; 31:447-451.

You Z, Luo C, Zhang W, Chen Y, He J, Zhao Q, Zuo R, Wu Y. Pro- and anti-inflammatory cytokines expression in rat's brain and spleen exposed to chronic mild stress: Involvement in depression. Behav Brain Res. 2011; 225:135-141. [PubMed: 21767575]

Ziegler DR, Cass WA, Herman JP. Excitatory influence of the locus coeruleus in hypothalamicpituitry-adrenocortical axis responses to stress. J Neuroendocrinol. 1999; 11:361-369. [PubMed: 10320563] 


\section{Highlights}

Stress system dysfunction influences depression pathophysiology

Parkinson's disease and depression have a high rate of comorbidity

Depression and motor symptoms in Parkinson's disease may be affected by stress

Development of new animal model to examine stress effects on injured dopamine cells 




Figure 1. Molecular and cellular effects of chronic stress

Chronic stress may impair neurons via several mechanisms. Chronic activation of the HPA axis results in hyperactive activation of the axis and increased levels of relevant hormones including corticotrophin-releasing hormone $(\mathrm{CRH})$, adrenocorticotropic hormone (ACTH), circulating glucocorticoids and impairment of dexamethasone feedback (Herman et al., 1995; Mizoguchi et al., 2008; Ulrich-Lai and Herman; 2009). Chronic stress results in an increased neuroinflammatory environment via increases in pro-inflammatory molecules such as interleukin-6 (IL-6), IL-1, tumor necrosis factor alpha (TNF $\alpha$ ), and nuclear factor kappa $\mathrm{B}(\mathrm{NF}-\kappa \mathrm{B})$ and decreases in anti-inflammatory molecules such as IL-10 and transforming growth factor beta (TGF $\beta$ ) (Grippo et al., 2005; You et al, 2011; Sun et al., 2011). Neurodegeneration increases in the hippocampus after chronic stress at least partly due to increased caspase-3 levels and decreased anti-apoptotic B-cell lymphoma (Bcl-2) levels (Bachis et al., 2008; Kosten et al., 2008; Yang et al., 2011). Dendritic atrophy occurs in several regions including the hippocampus and prefrontal cortex (Magariños and McEwen, 1995a, b; Wellman, 2001; Radley 2004; Cerqueira et al., 2005). Cellular oxidative stress also changes after chronic stress including increases in the superoxide radical $\mathrm{O}_{2}$ - and protein and lipid peroxidation (Lucca et al., 2009a, b; Ahmad et al., 2010; Tagliari et al., 2010). Loss of trophic support through decreases in brain-derived neurotrophic factor (BDNF) occurs in the hippocampus and prefrontal cortex after chronic stress (Smith et al., 1995; Song et al., 2006; Adzic et al., 2009). Lastly, chronic stress decreases neurogenesis in the hippocampus as indicated by the loss of bromodeoxyuridine (BrdU) positive cells (Gould and Tanapat, 1999; Pham et al., 2003). Together, these stress-induced cellular and molecular alterations create a harmful neuronal environment that could result in the presentation of depressive and other neuropsychiatric symptoms. 